\title{
Analysis of the Spray Characteristics of Water and Water/Glycerin Mixtures using an Interferometric Laser Imaging for Droplet Sizing Technique
}

\author{
Emir Yilmaz ${ }^{1}$, Takashi Suzuki¹, Kenji Ito², Gabriel J. Gotama ${ }^{3,4}$, Willyanto Anggono5,6, \\ Mitsuhisa Ichiyanagi $1^{*}$ \\ ${ }^{1}$ Sophia University, Department of Engineering and Applied Sciences, 7-1 Kioi-cho, Chiyoda-ku, Tokyo, 102-8554, \\ Japan \\ ${ }_{2}^{2}$ Sophia University, Graduate School of Science and Technology, 7-1 Kioi-cho, Chiyoda-ku, Tokyo, 102-8554, Japan \\ ${ }^{3}$ School of Mechanical and Aerospace Engineering, Nanyang Technological University, 50 Nanyang Ave., \\ Singapore 639798 \\ ${ }^{4}$ Department of Aerospace and Geodesy, Technical University of Munich, Willy-Messerschmitt-Str. 1, \\ Taufkirchen/Ottobrunn 82024, Germany \\ 5Mechanical Engineering Department, Petra Christian University, Jl. Siwalankerto No. 121-131, Surabaya, Jawa \\ Timur 60236, Indonesia \\ ${ }^{6}$ Centre for Sustainable Energy Studies, Petra Christian University, Jl. Siwalankerto No. 121-131, Surabaya, Jawa \\ Timur 60236, Indonesia
}

\begin{abstract}
Injection characteristics play an important role in the emission and overall thermal efficiency of an engine. Several methods have been proposed for analyzing different fuel injection characteristics. This study focused on the interferometric laser imaging for droplet sizing (ILIDS) technique to investigate the effects of droplet size and velocity under different conditions of waterglycerin mixtures. These effects were evaluated using intermittent spray flows in both ambient and pressurized constant volume spray chamber conditions. The initial results were compared to those reported by previous studies and used to determine the Sauter mean diameter (SMD), arithmetic mean diameter (AMD), droplet velocity, and probability density function of the spray droplet size. SMD and AMD tended to decrease as the plate temperature, injection pressure, and viscosity were increased at specific observation areas. The average velocity of the droplet increased with higher plate temperature and injection pressure at specific observation areas. The distribution of the smaller droplet increased with higher plate temperature and injection pressure. For the waterglycerin mixture, as the glycerin ratio increased, more viscous droplets were created. This was followed in higher nozzle shear force at the outlet of the fuel injector, which decreased the particle size and generated more atomized fuel sprays. This result can enable the reduction in hydrocarbon and carbon monoxide emissions from internal combustion engines.
\end{abstract}

Keywords: Fuel injection; ILIDS; Spray characteristic; Water-glycerin mixture

\section{Introduction}

As the impact of global warming becomes more evident, decarbonization, low carbon mobility, and zero impact emission vehicles are some new terms related to the process of lowering hazardous emissions in the transportation industry. Vehicle electrification has still plays a vital role in regions such as the Middle East, Southeast Asia, and South America. 
Biofuels and their blends with conventional fossil fuels, such as gasoline or diesel, are being studied in the context of reducing hazardous gas emissions. These emissions are directly related to the spray fuel properties and injection conditions; thus, it is critical to understand the spray behavior of the fuel blends under various engine conditions.

Various visualization techniques have been used in the literature to study the blending of biofuels. Patel et al. (2016) used phase Doppler interferometry to investigate droplet size and velocity distributions for Jatropha biodiesel blends up to $20 \%$. The results from Patel showed that with a higher concentration of Jatropha biodiesel, brake-specific carbon monoxide emissions reduced at higher engine speeds. In a more recent study that focused on the engine performance of biodiesel in a diesel engine, blends of avocado seed oil may substitute biodiesel mixtures from palm oil mill effluent blends with some reduction in power output (Sutrisno et al., 2019). Said et al. (2018) discovered that palm oil mill effluent blended with diesel fuel decreased $\mathrm{CO}_{2}, \mathrm{CO}$, and hydrocarbon emissions in various engine loads. However, the results also showed an increase in $\mathrm{NO}_{\mathrm{x}}$ emissions up to $5.9 \%$.

Atomization of liquids with high viscosity has been a challenge in various engineering applications when high speed and small diameter sprays are required. Garcia et al. (2017) analyzed Venturi-vortex twin-fluid swirl nozzle application for pure glycerin at room temperature. At 10 liter/hour flow rate, $26 \%$ of glycerin volume was atomized to droplets with a diameter of $20 \mu \mathrm{m}$. Liquid ligaments were present at the nozzle exit and tended to vanish moving away from the nozzle. However, the size distribution variations could not be identified by Garcia et al. (2017), who used laser diffractometry.

Although the potential usage of biofuels has been extensively investigated, these studies tend to focus solely on engine performance. However, combustion efficiency for ICEs is dependent on the injection characteristics, which tend to change with the different types of fuel used. To assess and control the combustion process more effectively, it is crucial to know the mechanism and the relationship behind the injection conditions and the fuel. In fact, new generation bio-fuels are highly viscous and multicomponent in nature. For this reason, the spray characteristics of these fuel blends need to be investigated as they present different physical properties, such as viscosity and surface tension. Typical methods for investigating spray characteristics involve particle image velocimetry (Adrian, 1991) and phase doppler interferometry (Kobashi et al., 1991). Unfortunately, these methods cannot simultaneously measure particle size, velocity, and spatial distributions, which are vital to understanding spray behavior. By contrast, the interferometric laser imaging for droplet sizing (ILIDS) method provides a clear spatial correlation between the particles and allows simultaneous measurement of particle size and velocity with improved accuracy. There have been various improvements in the ILIDS method, including the reduction of the overlap of interference images (Kawaguchi et al., 2002), higher resolution of the spray particles (Dehaeck and Van Beeck, 2008), and extended measurable particle size range (Hardalupas et al., 2010). In addition to these advanced techniques, Shigeta et al. (2012) improved the accuracy of the particle position detection, which enabled a simultaneous spatial mass flux evaluation.

The aim of this study was to explore the influence of viscosity and injection pressure for different ambient temperatures on droplet size and distribution to optimize the injection mechanisms. To this end, in this study, the ILIDS method was chosen as an effective method to evaluate and measure the characteristics of water-glycerin mixtures. This work focused on port injection conditions for naturally aspirated and supercharged engines. The working fluid was a water-glycerin mixture, which is easier to work with compared to fuel oils, as the composition of fuel oils is harder to control and analyze. Upon 
the validation of the experimental setup, various biofuel blends will be utilized to lower conventional ICEs $\mathrm{CO}_{2}$ emissions.

\section{Measurement and Evaluation Method}

\subsection{Measurement Principle of Interferometry}

ILIDS is a method of irradiating a particle with a laser sheet and observing the formed interference fringes in space due to a phase difference between reflected and refracted lights from a particle. Figure 1 a shows the measurement principle of the ILIDS method. The spray flow is measured in a two-dimensional cross-section by converting the laser into a sheet using two cylindrical lenses. As a result, in addition to individual particle information, the spatial distribution of the spray flow can be measured. The interference fringes become the sharpest when the intensity of the reflected light and the primary refraction light from the particle are equal, and the scattering angle of the droplet is about $73^{\circ}$. ILIDS technical specifications are given in Table 3 . Figure $1 \mathrm{~b}$ shows the schematic diagram of the lightreceiving optics for the improved ILIDS method. By incorporating two cylindrical lenses between the camera and the condenser lens, the vertical component is observed on the focal plane (Figure $1 \mathrm{~b}(\mathrm{~A})$ ), and the horizontal component necessary for measuring the number of fringes is observed on the non-focal plane (Figure $1 \mathrm{~b}(\mathrm{~B})$ ). As shown in Figure $1 \mathrm{~b}(\mathrm{C})$, it is possible to capture an interference fringe image when only the vertical component is compressed, which allows for the removal of overlapping images, resulting in the increased number of detected particles. Technical details about the ILIDS system for this experimental setup are provided in section 3.1 Experimental equipment and specifications.

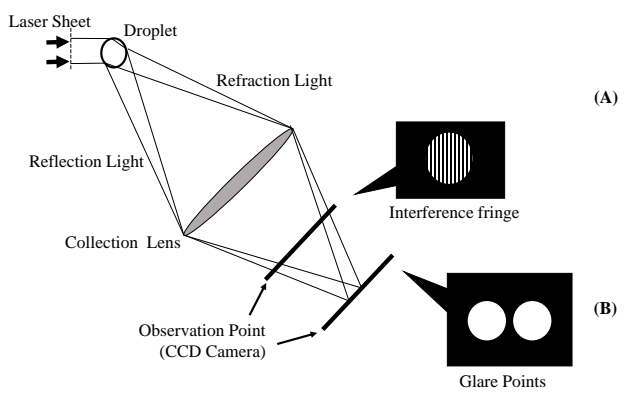

(a)

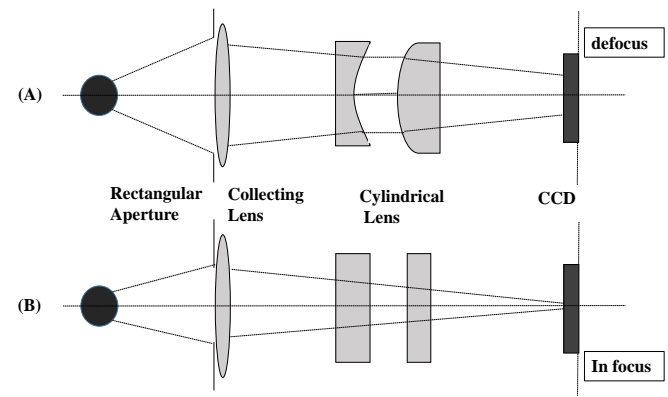

(b)

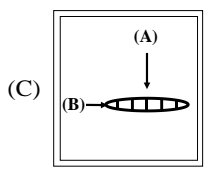

Figure 1 (a) Measurement principle of ILIDS; (b) evaluation methods of particle size and velocity

Originally, the particles are observed on the out-of-focus plane with the ILIDS. When a particle is observed at a focused plane, two bright points are observed due to the reflected and refracted lights, which are called glare points. Figure $1 \mathrm{a}$ shows the two different light paths from the reflected and refracted light particles. The images are then captured on the focal and non-focal image planes. It is possible to calculate the particle size from the distance between the glare points on the focal plane. However, this can result in two problems. First, it is difficult to judge the particles near the bright spots. Second, sufficient resolution and magnification are required, which scales up the optical system requirements. As a solution, particle size can be measured by observing the number of interference fringes by the ILIDS technique. The interference image could be compressed using a method proposed by Kawaguchi et al. (2002) and applied to a field with high droplet number density. 


\subsection{Calculation and Evaluation Methods of Particle Size, Position, and Velocity}

The relationship between the number of interference fringes, $N_{i}$, and the particle size is given in Equation 1, where $d$ is the particle size $(\mathrm{m}), \lambda_{i}$ is the laser wavelength $(\mathrm{m}), \theta$ is the acceptance angle (rad), $m$ is the relative refractive index of particle, and $\alpha$ is the lens focusing angle (rad). The parameters other than the $N_{i}$ depend on the conditions of the optical system and experimental equipment.

$$
d=\frac{2 \lambda_{l} N_{l}}{\alpha}\left(\cos \theta / 2+\frac{m \sin \theta / 2}{\sqrt{m^{2}-2 m \cos \theta / 2+1}}\right)^{-1}
$$

For particle position and velocity measurement, particle tracking velocimetry was used. Two continuous particle images were superimposed on a plate where dots were arranged at equal intervals, and the displacement of the particles was calculated from the number of moving dots, which were measured by the amount of pixel movements between two consecutive images. Particle velocities were calculated by dividing the moving distance and the photographing time interval. Measured error of the particle position was defined as 0.001 pixels, and particles with a movement range of 0.001 pixel or less were omitted as the error.

The mean particle diameter was calculated using Sauter mean diameter (SMD) to assess the spray behavior and expressed by Equation 2, where $n_{i}$ is the number of particles and $x_{i}$ is the particle size.

$$
S M D=\bar{x}=\frac{\sum n_{i} x_{i}^{3}}{\sum n_{i} x_{i}^{2}}
$$

SMD is calculated by dividing the sum of the volume of the particles by the sum of the surface areas, and the average particle size that correlates the surface area and volume of the particles can be calculated. As the evaporation rate of particles is proportional to the surface area, the mass evaporation rate of the spray is proportional to this SMD size. Additionally, collision Weber number, $W e_{c o l}$, was used to evaluate the change in particle shape, and expressed with the liquid density, $\rho_{l}\left(\mathrm{~kg} / \mathrm{m}^{3}\right)$, relative velocity between two colliding droplets, $U_{r e l}(\mathrm{~m} / \mathrm{s})$, droplet diameter, $d_{o}(\mathrm{~m})$, and surface tension, $\sigma_{l}\left(\mathrm{~kg} / \mathrm{s}^{2}\right)$, as in Davanlou et al. (2015):

$$
W e_{c o l}=\rho_{l} U_{r e l}^{2} d_{o} / \sigma_{l}
$$

Assuming that the collision of spray particles is a head-on collision with the same diameter, $U_{r e l}$ was regarded as twice the droplet velocity (Davanlou et al., 2015). The coalescence probability of the particles was calculated by Equation 4 (Saha et al., 2012). The critical Weber number, $W e_{\text {crit }}$, is expressed in Equation 5, which is related to the collision Ohnesorge number, $\mathrm{Oh}_{c o l}$, as in Equation 6. Particle breakup time, $t_{b}$ [s], is expressed in Equation 7 with gas density, $\rho_{g}\left(\mathrm{~kg} / \mathrm{m}^{3}\right)$ (Hisiang and Faeth, 1992). The shear stress, $\tau(\mathrm{Pa})$, acting on the particles is expressed by Equation 8 using the nozzle diameter, $h(\mathrm{~m})$, and $\mu$ as the viscosity coefficient $(\mathrm{Pa} \cdot \mathrm{s})$ :

$$
\begin{gathered}
\text { Coalescence Probability }=\frac{\text { Number of droplets with } W e \leq W e_{\text {crit }}}{\text { Total number of droplets }} \\
\begin{array}{c}
W e_{c r i t}=30 O h_{c o l}+15 \\
O h_{c o l}=16 \mu_{l} / \sqrt{\rho_{l} \sigma_{l} d_{o}}
\end{array}
\end{gathered}
$$




$$
\begin{gathered}
t_{b}=\frac{d_{0} \sqrt{\rho_{l} / \rho_{g}}}{U_{0}} \times 5.0 \\
\tau=\mu \frac{U_{0}}{h}
\end{gathered}
$$

\section{Experimental Equipment and Conditions}

\subsection{Experimental Equipment and Specifications}

In order to replicate the atomization results for fuel oil sprays, the water-glycerin mixture with different ratios were used throughout the experiments. Figure 2a shows a schematic diagram of the experimental setup and the injection pattern used in this study. For spray generation, a solid cone-type nozzle was used, and distilled water along with glycerin solution were used as the working fluids. The injection nozzle was a single hole solid cone type, with a flowrate range of $0-35 \mathrm{cc} / \mathrm{min}$. The nozzle diameter of the working fluid was $0.69 \mathrm{~mm}$, whereas it was $1.69 \mathrm{~mm}$ for air. The injection pattern and timing chart are shown in Figure $2 \mathrm{~b}$. The injection time was $200 \mathrm{~ms}$, and the interval of the trigger pulse was 66.6 ms. The delay of laser beams 1 and 2 were $300 \mu$ s and $300+\Delta t$ from the trigger pulse, respectively. In this case, $\Delta t$ became the interval time of the pair image. We chose the appropriate interval time (5-150 $\mu \mathrm{s}$ ) and exposure time (274-348 $\mu \mathrm{s})$ depending on the velocity of the droplet in each experiment. Spray injection was repeated, and images were captured until the data converged. The average sample size for the experiments was calculated as 7000. An electromagnetic valve and a delay circuit between the tank and the nozzle were used to control the injection timing to generate the intermittent spray flow. A constant volume vessel with an inner diameter of $122 \mathrm{~mm}$ and height of $153 \mathrm{~mm}$ with quartz glass installed on the laser incident, emission, and imaging directions was used for the spray measurements. A compressor was used for injection pressure and pressurization of the vessel, which controlled by a regulator. Table 1 shows experimental specifications.

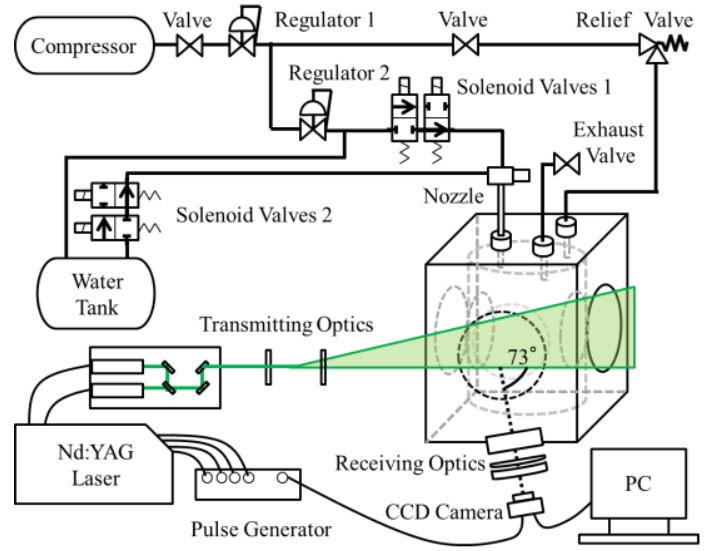

(a)

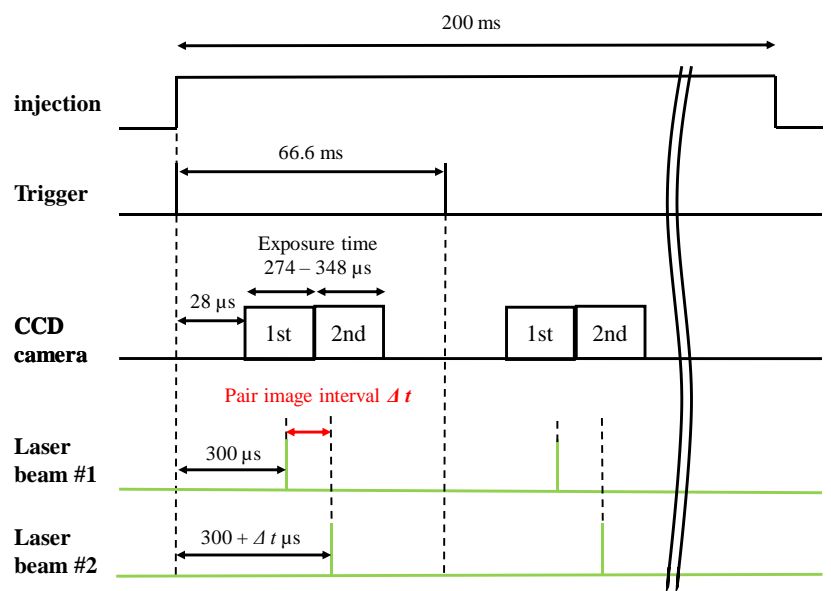

(b)

Figure 2 Schematic of: (a) Experimental setup; (b) injection pattern and timing chart

$\mathrm{Nd}$ :YAG laser with a wavelength of $532 \mathrm{~nm}$, maximum output power of $30 \mathrm{~mJ} /$ pulse, and a repetition frequency of $30 \mathrm{~Hz}$ was used in this study. The height of the laser sheet was $30 \mathrm{~mm}$ and the thickness at the test section was $1 \mathrm{~mm}$. Considering the dynamic range of the CCD camera used in this experiment, it was necessary to use a laser with circular polarization to irradiate the spray, and therefore the emitted laser was converted from linear to circular polarization using a quarter-wave $(\lambda / 4)$ plate. 
Table 1 Specifications of the experimental setup

\begin{tabular}{lc}
\hline \multicolumn{1}{c}{ Instruments } & Specifications \\
\hline Working fluid & Distilled water and glycerin mixture \\
Nozzle & Single hole; solid cone type \\
Flowrate range & $0-35 \mathrm{cc} / \mathrm{min}$ \\
Nozzle diameter of air; fluid & $1.69 \mathrm{~mm} ; 0.69 \mathrm{~mm}$ \\
Chamber size & $\Phi 122 \times \mathrm{H} 153 \mathrm{~mm}$ \\
Laser model & Solo II-30 Hz \\
Laser type & Double Pulse; Nd:YAG laser $532 \mathrm{~nm}$ \\
CCD camera & ICL-B2520M-SC000 \\
CCD camera specifications & $2448 \times 2050$ pixels \\
Observation area & $12 \times 10 \mathrm{~mm}$ \\
Measurable droplet range & $14-450 \mu \mathrm{m}$ \\
\hline
\end{tabular}

The CCD camera has $4.8 \mu \mathrm{m} /$ pixel spatial resolution. The diameter resolution is calculated to be $0.72 \mu \mathrm{m}$ by using the wavelet transform method with stripes up to 0.1 . Velocity measurement resolution of $0.098 \mathrm{~m} / \mathrm{s}$ is used to consider the subpixel. Laser beam firing and imaging timings were controlled by a pulse generator. The light-receiving optical system has a short aperture ( $4 \mathrm{~mm} \times 28 \mathrm{~mm}$ ) in front of the condenser lens (focal length: $135 \mathrm{~mm}, \mathrm{~F}$-number: 2) for adjusting the measurement range of the particle size, resolution, and depth of field. By changing the length of the long side of the rectangular aperture, the converging angle could be modified, which results in the adjustment of the number of interference fringes for the same particle size. Details of the resolutions are provided in Table 2.

Table 2 Resolution specifications

\begin{tabular}{lc}
\hline \multicolumn{1}{c}{ Camera and Lens Properties } & Specifications \\
\hline Spatial resolution & $4.8 \mu \mathrm{m} / \mathrm{pixel}$ \\
Particle size resolution & $0.72 \mu \mathrm{m}$ \\
Velocity measurement resolution & $0.098 \mathrm{~m} / \mathrm{s}$ \\
\hline
\end{tabular}

As explained earlier, minimum measurable particle size was determined by Equation 1, and for these experiments, the number of the lowest stripe was 2 . The value of the diameter per fringe was $7 \mu \mathrm{m}$, and thus the minimum measurable particle size was approximately $14 \mu \mathrm{m}$. The maximum measurable particle size was determined by the number of highest stripe, which was $L / 4$, where $L$ is the length of the fringe pattern in pixels (Sahu, 2011).

Table 3 Specifications of the ILIDS system

\begin{tabular}{|c|c|}
\hline Nozzle, optics, and Lenses & Specifications \\
\hline \multicolumn{2}{|l|}{ Transmitting optics } \\
\hline Cylindrical lens focal length & $-30,30 \mathrm{~mm}$ \\
\hline Spherical lens focal length & $300 \mathrm{~mm}$ \\
\hline \multicolumn{2}{|l|}{ Receiving optics } \\
\hline Cylindrical lens focal length & $-50,50 \mathrm{~mm}$ \\
\hline Distance between camera and object & $58 \mathrm{~cm}$ \\
\hline Rectangular aperture & $4 \times 28 \mathrm{~mm}$ \\
\hline Receiving angle & $73^{\circ}$ \\
\hline \multicolumn{2}{|l|}{ Collecting lens } \\
\hline Focal length & $135 \mathrm{~mm}$ \\
\hline F-number & 2 \\
\hline Observation area & $12 \times 10 \mathrm{~mm}^{2}$ \\
\hline Collection angle & $4.61^{\circ}$ \\
\hline
\end{tabular}


In this experiments $L$ was 250 pixels, thus the number of highest stripes was 62.5 and the maximum measurable particle size was $450 \mu \mathrm{m}$. The measurable particle size was set to 14-450 $\mu \mathrm{m}$ (droplets with smaller or bigger diameter than this range were kept out of scope). The depth of field during the shooting was adjusted by changing the length of the short side of the rectangular aperture, which was made sufficiently short to focus on the entire imaging plane with the collecting and receiving angles set to $4.6^{\circ}$ and $73^{\circ}$, respectively. Details are provided in Table 3. For experiment 4 , the properties of the working fluids used in this study are listed in Table 4 . The values of surface tension and viscosity for water-glycerin mixtures were set to replicate the properties of biofuel oils.

Table 4 Water-Glycerin mixture properties at ambient conditions

\begin{tabular}{ccccc}
\hline $\begin{array}{c}\text { Water-glycerin } \\
\text { mixture ratio }\end{array}$ & Refractive index & $\begin{array}{c}\text { Dynamic viscosity } \\
(\mathrm{mPa} \cdot \mathrm{s})\end{array}$ & $\begin{array}{c}\text { Surface tension } \\
(\mathrm{mN} / \mathrm{m})\end{array}$ & $\begin{array}{c}\text { Density } \\
\left(\mathrm{g} / \mathrm{cm}^{3}\right)\end{array}$ \\
\hline $0 \%$ & 1.333 & 1.131 & 72.75 & 1.009 \\
$15 \%$ & 1.351 & 1.537 & 71.42 & 1.040 \\
$30 \%$ & 1.371 & 2.227 & 70.75 & 1.073 \\
$60 \%$ & 1.413 & 10.81 & 68.31 & 1.154 \\
\hline
\end{tabular}

\subsection{Experimental Conditions}

Table 5 shows the experimental conditions of this study, where four different experimental conditions were used. Notations $z$ and $r$ in Table 5 are the axial and radial distances from the nozzle, respectively. For Experiment 1, an A5052 flat plate with width and length of $150 \mathrm{~mm}$ and thickness of $15 \mathrm{~mm}$ was heated to $473 \mathrm{~K}$ by a burner in ambient conditions. The plate was installed $310 \mathrm{~mm}$ below the nozzle to determine the effect of the temperature change of the flat plate on the spray in ambient pressure conditions. For Experiment 2, an A5052 flat plate with a width and length of $60 \mathrm{~mm}$ and a thickness of 3 $\mathrm{mm}$ was placed $140 \mathrm{~mm}$ below the nozzle to investigate the effect of temperature change of the heated plate on the spray behavior in a constant volume spray chamber. A ceramic heater was used to alter the temperature of the ambient condition. The kinematic viscosity of glycerin at ambient conditions $\left(1042 \times 0^{-6} \mathrm{~m}^{2} / \mathrm{s}\right)$ is much higher than that of the preheated heavy fuel oils (at $50^{\circ} \mathrm{C}$ approximately $640 \times 10^{-6} \mathrm{~m}^{2} / \mathrm{s}$ ) (Garcia et al., 2017).

In Experiment 3, injection pressure was varied to assess its effect on the spraying behavior in ambient conditions. In Experiment 4, glycerin solution was used as the working fluid with different ratios in ambient conditions to assess the effect of viscosity on spray behavior. In this study, the probability density function, arithmetic mean diameter (AMD), SMD, and average velocity were measured. It should be noted that the pressure in this experiment was a gauge pressure, with the atmospheric pressure set to $0 \mathrm{MPa}$.

Table 5 Sets of experiment and experimental conditions

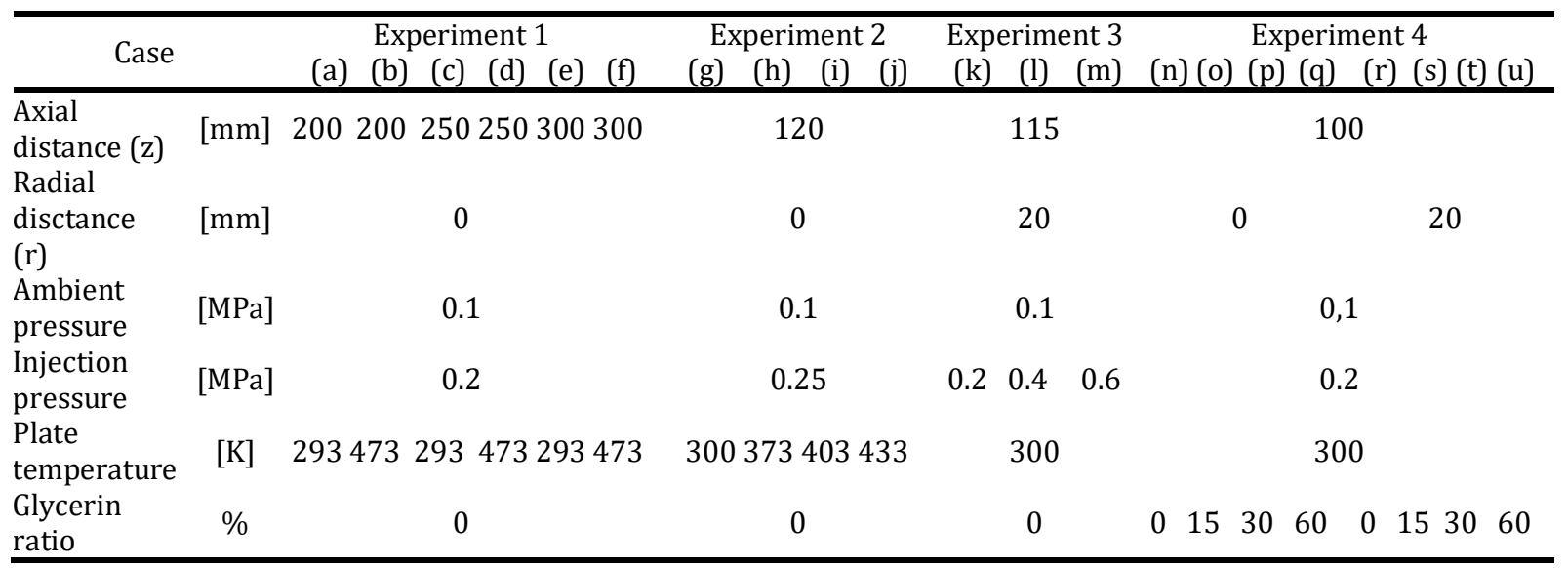


The probability distributions during these tests showed a Gaussian trend. Standard deviation, $\sigma$, and bias error were calculated as 3.72 and $7.44(2 \sigma$, for $95 \%$ confidence level uncertainty), respectively. The uncertainty analysis for this experimental setup was performed using the RSS method (ISO, 2005), which was calculated as $6.0 \%$. The level of uncertainty analysis was decided to be an adequate level for an experimental study.

\section{Results and Discussion}

\subsection{Effect of Heated Plate on the Particle Size and Speed in Ambient Conditions}

\section{(Experiment 1)}

Figure 3a shows the results of evaluating SMD and AMD for each heating area with and without heating under the conditions of ambient pressure after the impact on the heated plate. Based on Figure 3a, the SMDs and AMDs were reduced by heating the flat plate for all observation areas. This is related to the evaporation of the particles accelerated by the heated-plate and its surroundings. The larger difference between non-heated SMD and AMD can be explained with Equation 2. The nominator in Equation 2 (sum of the volume of the particle) has an exponential factor of 3 on the particle size, whereas the denominator (sum of the surface area of the particle) only has a factor of 2 . Given that in ambient conditions, evaporation effect is reduced and results in the larger particle size, a large increase in SMD becomes apparent as the difference between the volume and surface area of the particles increases. The change is significant, such that even a small increase in droplet diameter could result in a big difference between SMD and AMD, especially when compared to the results in a heated-plate case. By contrast, water spray droplet diameters were found to be 40-60 $\mu \mathrm{m}$, which was similar to the results from previous studies (Damaschke et al., 2005; Hardalupas et al., 2010). The coalescence probability was obtained from Equation 6 as (a) 27.2\%, (b) 20.4\%, (c) 56.9\%, (d) 44.1\%, (e) 54.3\%, (f) 54.3\%, which was reduced by higher temperature of the flat plate. The average breakup time of the particles obtained from Equation 7 were calculated as (a) $2.0 \mathrm{~ms}$, (b) $1.1 \mathrm{~ms}$, (c) $5.1 \mathrm{~ms}$, (d) $4.1 \mathrm{~ms}$, (e) $2.8 \mathrm{~ms}$, (f) $4.0 \mathrm{~ms}$. The results showed that $t_{b}$ was reduced by heated the plate.

Figure $3 \mathrm{~b}$ shows the average vertical velocity of particles under the conditions of Experiment 1. It was found that the average velocity of the particles increased with the heated plate for all observation points, which decreased the coalescence probability and breakup time, $t_{b}$. The axial velocity differences between small and big droplets are linked to the bouncing effect. Bigger droplets tend to overcome the evaporation effect of the heated plate more easily due to their size, thus reaching and bouncing off in the opposite direction. Because of this change in direction, the average axial velocity for bigger droplets is reduced.

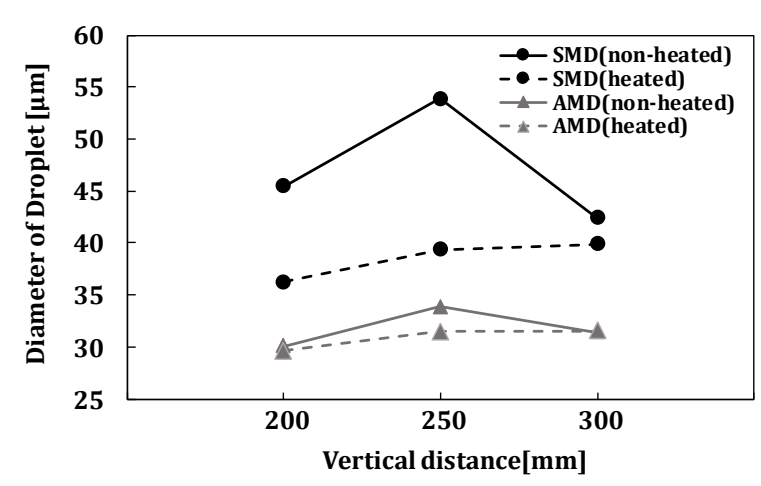

(a)

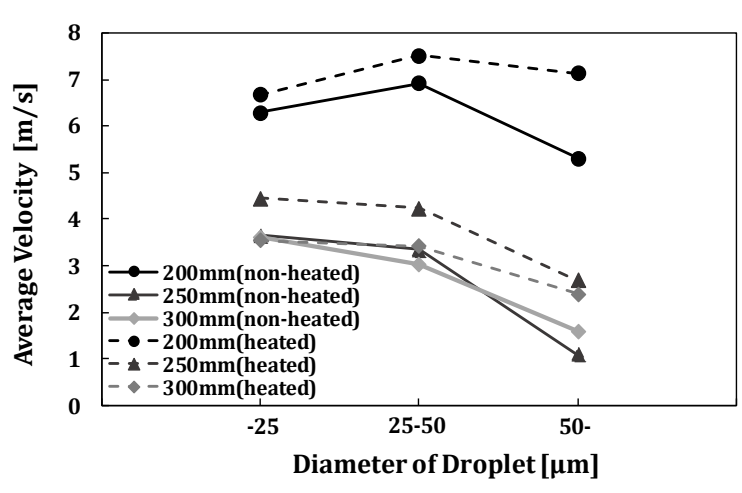

(b)

Figure 3 (a) SMD and AMD; (b) average droplet velocity for Experiment 1 


\subsection{Effect of Plate Temperature on the Particle Size and Speed in a Constant Volume Spray Chamber (Experiment 2)}

Figure 4a shows the results of the evaluation of SMD and AMD for various heating temperatures of the plate. AMD decreased as the heating temperature increased due to the increased effect of evaporation. A similar tendency was obtained for the SMD, except for the results for condition (i). As previously explained, SMD is the ratio of the sum of cubed and the sum of squared particle diameters, and therefore the effect of large-diameter particles appears to affect the final SMD value significantly. Here, the total number of samples under each condition was observed as $(g) 2693,(h) 1767,(i) 1326,(j) 1477$. The increase in SMD for $(i)$ is considered to be related to the effect of fewer samples.

Figure $4 \mathrm{~b}$ shows the average vertical velocity of particles. The average velocity increased for all particle sizes by increasing the temperature of the heated plate. Similar to the analysis in Experiment 1, these results suggest that the decrease in the coalescence probability and breakup time due to the increase in the temperature results in an increase in the average velocity of the spray particles.

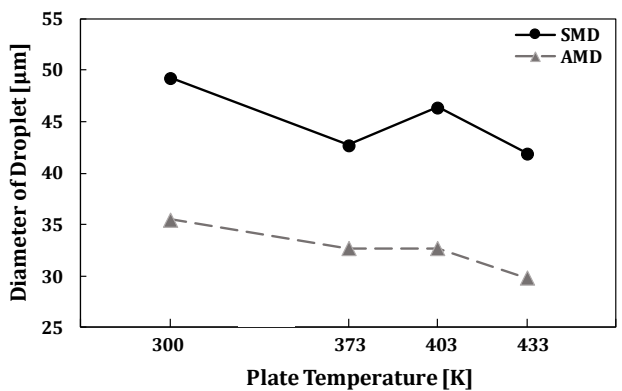

(a)

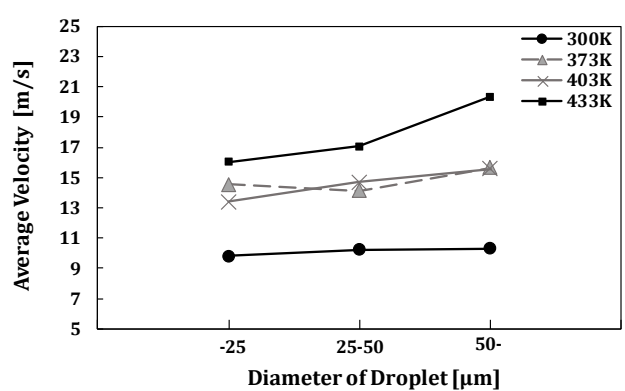

(b)

Figure 4 Comparison of: (a) SMD and AMD; (b) average droplet velocity under the conditions of Experiment 2

Figure 5 shows the probability density function results of the particle size for each heating temperature. The presence ratio of particles having $25 \mu \mathrm{m}$ or less was $(g) 27.1 \%$, (h) $31.9 \%$, (i) 34.8\%, (j) 44.6\%, and the presence ratio of $50 \mu \mathrm{m}$ or more was $(g) 22.4 \%$, $(h)$ $16.1 \%$, (i) $15.8 \%$, and (j) $12.3 \%$.

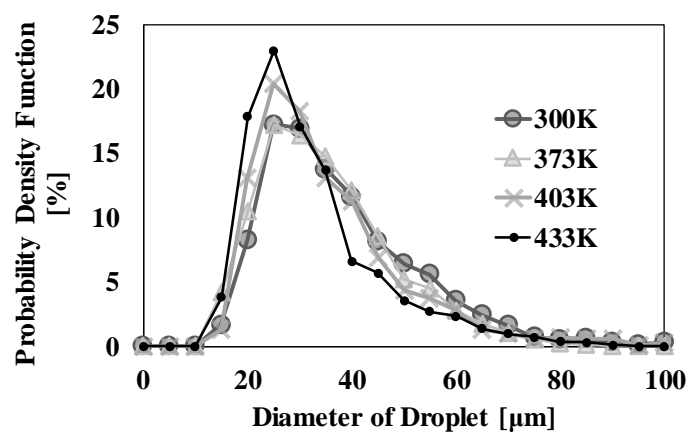

Figure 5 Probability density function of droplet diameter under the conditions of Experiment 2

The results showed that large-diameter particles decreased, and small-diameter particles increased as plate temperature increased. This is due to the evaporation induced transition of large-diameter particles to smaller ones. The coalescence probability of the particles was also decreased with increasing temperature and was calculated from 
Equation 6 as $(g)$ 23.1\%, (h) 3.5\%, (i) 2.4\%, and (j) 1.2\%. Further, from Equation 7, the average breakup time of the particles was $(g) 2.8 \mathrm{~ms}$, (h) $0.47 \mathrm{~ms}$, (i) $0.43 \mathrm{~ms}$, and $(j) 0.29$ ms. These results also indicate that $t_{b}$ decreases with increasing heating temperature, causing a smaller diameter spray range $(20-40 \mu \mathrm{m})$ to be more prevalent.

\subsection{Effect of Injection Pressure on Particle Size and Speed (Experiment 3)}

Figure 6a shows the results of SMD and AMD for each injection pressure under the conditions of Experiment 3. From Figure 6a, both SMD and AMD were found to decrease as the injection pressure increased. These results show that the breakup time decreases with increased injection pressure, which was calculated by Equation 7 as $(k) 25 \mathrm{~ms}$, $(l) 9.1 \mathrm{~ms}$, and $(\mathrm{m}) 8.7 \mathrm{~ms}$. This suggests that the decrease in the average particle size is due to the increase in the injection pressure, which enhances the particle breakup time.

Figure $6 \mathrm{~b}$ depicts the average vertical velocity of particles. An increase in injection pressure resulted in an increase in the average particle velocity for all particle diameters. However, when compared with the condition $(k)$, there were no significant changes under the condition of $(l)$ and condition $(m)$. This is related to the increase in air resistance caused by injection pressure. At $0.2 \mathrm{MPa}$, air resistance values for particles $25 \mu \mathrm{m}, 25-50 \mu \mathrm{m}$, and $50 \mu \mathrm{m}$ were $898.5 \mathrm{~N}, 2182.0 \mathrm{~N}$, and $2237.1 \mathrm{~N}$, respectively. A similar trend was found in other cases, where at $0.6 \mathrm{MPa}$ the values were $858.5 \mathrm{~N}, 2617.5 \mathrm{~N}$, and $2683.6 \mathrm{~N}$, respectively. At these conditions of $0.4 \mathrm{MPa}$ and $0.6 \mathrm{MPa}$, the velocity of large-diameter particles was faster than that of small particles. This was due to the increased inertial forces for largesized particles calculated for $25 \mu \mathrm{m}, 25-50 \mu \mathrm{m}$, and $50 \mu \mathrm{m}$ as $44.9 \mathrm{~N}, 151.8 \mathrm{~N}$, and $259.7 \mathrm{~N}$, respectively, in the case of $0.2 \mathrm{MPa}$.

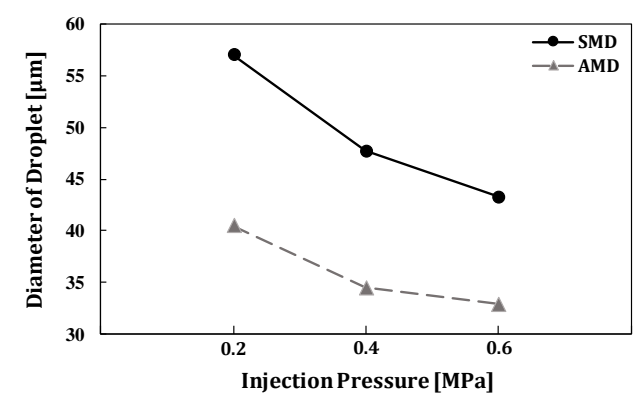

(a)

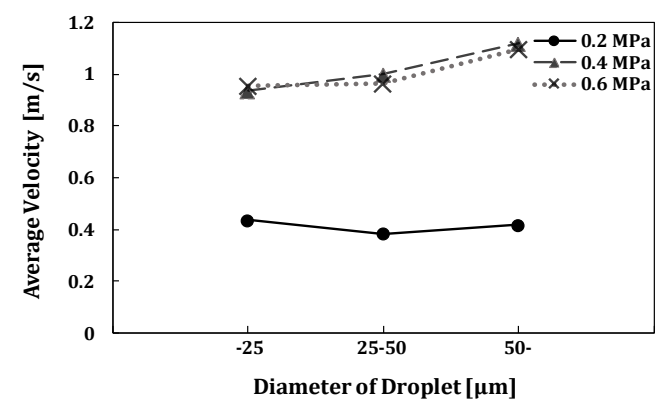

(b)

Figure 6 (a) SMD and AMD; (b) average droplet velocity for Experiment 3

\subsection{Effect of Working Fluid Viscosity on Particle Size (Experiment 4)}

Figures $7 \mathrm{a}-7 \mathrm{~b}$ depict the results for SMD and AMD under the conditions of Experiment 4. According to Figure 7a, a slight increase in SMD and AMD was observed just below the nozzle, which was in line with the results obtained from previous studies (Yao et al., 2012), as higher viscous sprays tend to have higher sizes. By contrast, when the standard deviation of the particle size was calculated, there was an increase with increasing viscosity, which were calculated as $(n) 16.4 \mu \mathrm{m},(o) 18.9 \mu \mathrm{m},(p) 21.5 \mu \mathrm{m},(q) 22.0 \mu \mathrm{m}$. It was apparent that the average particle size was almost the same just below the nozzle due to the increased viscosity, but the dispersion of the particle size increased.

As shown in Figure 7b, SMD and AMD were both decreased as the viscosity and radial distance increased. The ratios were found as $(r)$ 20.5\%, $(s)$ 16.5\%, $(t)$ 14.9\%, and $(u) 12.6 \%$. For the glycerin mixture ratios of $0 \%, 15 \%, 30 \%$, and $60 \%$, the shear stress at the nozzle acting on the particles was calculated using Equation 8 as $(r) 5.0 \mathrm{~Pa},(s) 6.8 \mathrm{~Pa},(t) 9.1 \mathrm{~Pa}$, and $(u)$ 44.6 $\mathrm{Pa}$, respectively. This suggested that particle size decreases due to increased 
nozzle shear force from the higher viscosity. Normally, for water, both SMD and AMD increase linearly with liquid flow rate and distance from the nozzle. However, for the increased glycerin ratio in the mixture, the opposite phenomenon was observed as particles moved away from the nozzle. This was most likely due to the presence of liquid ligaments that are fragmented as droplets at lower injection pressures $(0.2 \mathrm{MPa}$, to replicate the port injection conditions). As shown in Table 4, surface tension was smaller as the glycerin ratio was increased in the mixture. The reason for this is that relative velocity between the liquid film and air creates an instability that allows the liquid film to break into ligaments. The ligaments are then atomized into smaller droplets. These results are consistent with previous studies by Davanlou et al. (2015); Garcia et al. (2017).

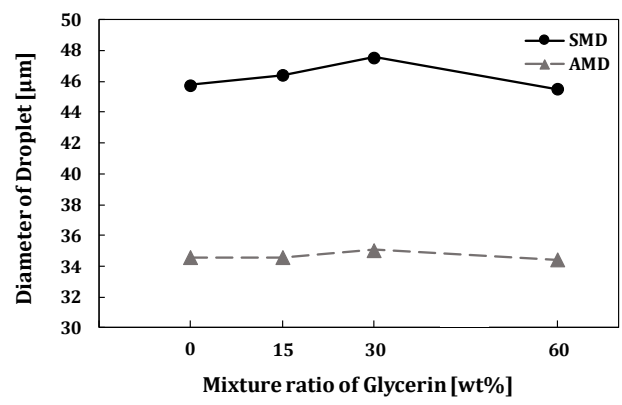

(a)

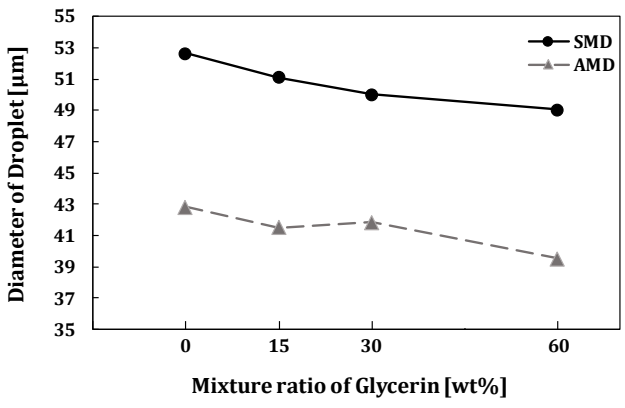

(b)

Figure 7 SMD and AMD at $\mathrm{z}=100 \mathrm{~mm}$ : (a) $\mathrm{r}=0 \mathrm{~mm}$; (b) $\mathrm{r}=20 \mathrm{~mm}$ for Experiment 4

\section{Conclusions}

ILIDS technique was used to investigate the effects of temperature, injection pressure, and different viscosities on the spray behavior in ambient and pressurized conditions. The findings of this study are summarized as follows: (1) For distilled water in ambient conditions, SMD and AMD were reduced due to the effect of the heated plate. For all particles, the average velocity increased with plate temperature; (2) As the plate temperature increased, the ratio of small-sized particles increased. The average velocity of the droplets increased with a higher plate temperature. However, SMD and AMD decreased with increasing temperature. These observations were all related to the evaporation effect on the spray; (3) As the injection pressure increased, the ratio of small-sized particles increased. SMD and AMD were both decreased with increasing injection pressure due to the nozzle shear effect. On average, droplet velocities increased as the injection pressure increased; and (4) When the viscosity of the working fluid was changed in ambient conditions, SMD and AMD were slightly increased. At the nozzle exit, the standard deviation increased as the variation in particle size increased. Additionally, for the higher viscous fluids where the glycerin ratio was increased, the growing rate of the droplet diameter became smaller as the radial distance increased. This phenomenon is related to the presence of liquid ligaments that are fragmented as the droplets moved away from the nozzle.

Measurement range for the observation area was $12 \times 10 \mathrm{~mm}^{2}$ and measurable spray droplets ranged between $14-450 \mu \mathrm{m}$. As the next step of this study, current experimental apparatus with various biofuel blends are aimed to be analyzed in order to understand the spray particle distribution and reduce exhaust emissions.

\section{Acknowledgements}

This work was supported by the Japan Society for the Promotion of Science, Grants-inAid for Scientific Research (No.19K04244). 


\section{References}

Adrian, R.J., 1991. Particle-Imaging Techniques for Experimental Fluid Mechanics. Annual Review of Fluid Mechanics, Volume 23, pp. 261-304

Damaschke, N., Nobach, H., Nonn, T.I., Semidetnov, N., Tropea, C., 2005. Multi-Dimensional Particle Sizing Techniques. Experiments in Fluids, Volume 39, pp. 336-350

Davanlou, A., Lee, J.D., Basu, S., Kumar, R., 2015. Effect of Viscosity and Surface Tension on Breakup and Coalescence of Bicomponent Sprays. Chemical Engineering Science, Volume 131, pp. 243-255

Dehaeck, S., Van Beeck, J.P.A.J., 2008. Multi Frequency Interferometric Particle Imaging for Gas Bubble Sizing. Experiments in Fluids, Volume 45, pp. 823-831

Garcia, J.A., Lozano, A., Alconchel, J., Calvo, E., Barreras, F., Santolaya J.L., 2017. Atomization of Glycerin with a Twin-Fluid Swirl Nozzle. International Journal of Multiphase Flow, Volume 92, pp. 150-160

Hardalupas, Y., Sahu, S., Taylor, A.M.K.P., Zarogoulidis, K., 2010. Simultaneous Planar Measurement of Droplet Velocity and Size with Gas Phase Velocities in a Spray by Combined ILIDS and PIV Techniques. Experiments in Fluids, Volume 49, pp. 417-434

Hisiang L.P., Faeth, G.M., 1992. Near-Limit Drop Deformation and Secondary Breakup. International Journal Multiphase Flow, Volume 18(5), pp. 635-652

International Organization for Standardization (ISO), 2005. Measurement Uncertainty for Metrological Applications-Repeated Measurements and Nested Experiments. ISO/TS 21749:2005

Kawaguchi, T., Akasaka, Y., Kobayashi, T., Maeda, M., 2002. Applications of Interferometric Laser Imaging Technique to the Spatial Analysis on Transient Spray Flow. Transactions of the Japan Society of Mechanical Engineers (B), Volume 68(666), pp. 576-583

Kobashi, K., Hishida, K., Maeda, M., 1991. Measurement of Fuel Injector Spray Flow of I.C. Engine by FFT Based Phase Doppler Anemometer. Applications of Laser Techniques to Fluid Mechanics, Springer, Berlin, pp. 268-287

Patel, C., Sharma, N., Tiwari, N., Agarwal, A.K., 2016. Effects of Spray Droplet Size and Velocity Distributions on Emissions from a Single Cylinder Biofuel Engine. In: SAE 2016 World Congress and Exhibition, United State

Said, N.H., Ani, F.N., Said, M.F.M., 2018. Emission and Performance Characteristics of Waste Cooking Oil Biodiesel Blends in a Single Direct Injection Diesel Engine. International Journal of Technology, Volume 9(2), pp. 238-245

Saha, A., Lee, J.D., Basu, S., Kumar, R., 2012. Breakup and Coalescence Characteristics of a Hollow Cone Swirling Spray. Phys. Fluids, Volume 24, https://doi.org/10.1063/1.4773065

Shigeta, Y., Hayashi, K., Ichiyanagi, M., Hishida, K., 2012. Measurement of Droplet Size, Velocity and Spatial Distribution of Mass Flux in Spray by Combining Focus and Defocus Imaging Technique. Transactions of the Japan Society of Mechanical Engineers (B), Volume 78(788), pp. 867-880

Sahu, S., 2011. Experimental Study of Isothermal and Evaporative Sprays. Master's thesis, Graduate Program, Imperial College London

Sutrisno, T., Anggono, W., Suprianto, F.D., Santosa, C.D., Suryajaya, M., Gotama, G.J., 2019. Experimental Investigation of Avocado Seed Oil Utilization in Diesel Engine Performance. International Conference on Automotive, Manufacturing, and Mechanical Engineering, Volume 130, pp. 1-10

Yao, S., Zhang, J., Fang, T., 2012. Effect of Viscosities on Structure and Instability of Sprays from a Swirl Atomizer. Experimental Thermal and Fluid Science, Volume 39, pp. 158166 